\title{
Biochemical and physiological responses to polyethylene glycol (PEG) treatment in protocorm-like bodies (PLBs) of Aranda Broga Blue Bell
}

\author{
Mohd. Aminur Faiz Suis ${ }^{1}$, Khor Soo Ping ${ }^{1}$, Chin Chee Keong, Sreeramanan Subramaniam ${ }^{\text {* }}$ \\ ${ }^{1}$ School of Biological Sciences, Universiti Sains Malaysia, Georgetown, 11800 Penang, Malaysia
}

\section{A B S T R A C T}

\begin{abstract}
Effects of different concentrations of polyethylene glycol 400 (PEG 400) on viability, relative water content, total chlorophyll content, total soluble protein and antioxidant enzymes activities of protocorm-like bodies (PLBs) of Aranda Broga Blue Bell orchid hybrid were determined. Different concentrations of in vitro drought-inducing chemical, PEG 400 at 0, 5, 10, and 15\% (v/v) were used in this study. From the results obtained, lower concentration of PEG 400 at $5 \%$ produce minimum impact on the relative water content and morphological changes of treated PLBs. Percentage of viable PLBs at 5\% PEG 400 treatment showed no significant difference with the control PLBs. However, significant reduction in total chlorophyll content and total soluble protein content of PLBs verified that supplementation of PEG 400 into Vacin and Went medium caused severe interruptions on various biochemical processes. Excessive production of free radical molecules increased the total activity of superoxide dismutase (SOD), catalase (CAT) and ascorbate peroxidase (APX). Specific localization, affinity and role of these enzymes resulted in different patterns of their overall activity. These findings suggested that the PLBs of $A$ randa Broga Blue Bell were drought tolerant orchid explants at low intensity of in vitro drought stress condition.
\end{abstract}

Abbreviations: PLBs (Protocorm-like bodies), PEG (Polyethylene glycol), PVP (Polyvinylpyrrolidone), ROS (Reactive oxygen species), NBT (Nitro blue tetrazolium chloride), SOD (Superoxide dismutase), CAT (Catalase), APX (Ascorbate peroxidase)

Keywords: PLBs; Polyethylene glycol; Drought stress; Chlorophyll content; Antioxidant enzyme

\section{INTRODUCTION}

Orchids, the doyen among all ornamental plants have a broad range of diversity in shape, size and colour of blossoms and their stunning beauty has enchanted and captivated people since early times. Orchidaceae is considered as the largest family in the plant kingdom which comprised of 20000 to 30000 species (Godo et al., 2010). There are more than 150000 artificial hybrids that have been cultivated worldwide (Yue et al., 2006). Such situation is a result of the greater degree of similarity among genera and species (Paek et al., 2011). Aranda orchids are intergeneric hybrids between member species and species hybrids of two natural genera in family Orchidaceae, Vanda and Arachnis (Lee 1991). Over the past five and half decades, more than 170 first generations of Aranda hybrids have been bred artificially and appear as foundation of orchid industry in the tropics (Lee 1987; Gantait and
Sinniah 2012). As reviewed by Zainol (2003), Aranda orchid hybrids have contributed with great impact to the early growth of the Malaysian cut flower industry in 1970s till mid 1990s. However, after 1990s the number of Aranda hybrid cultivated for cut flower production is decreasing due to the lack of suitable varieties (Zainol 2003). Presently, Aranda Broga Blue Bell a hybrid resulting from the cross between Mokara Wangsa Gold and Vanda coerulea have been developed to refresh the cut flower industry.

Drought stress is considered as one of the most significant abiotic factors that result in reduction of growth and development of many plants (Khodarahmpour 2011). During drought stress, the absorption of water molecules from soil become more difficult for the plants since the water potential in the rhizosphere is lower compared to that of root cells. Moreover, the efficiency and rate of photosynthesis are also greatly reduced. This is due to

*Corresponding author:

Sreeramanan Subramaniam, School of Biological Sciences, Universiti Sains Malaysia, Georgetown, 11800 Penang, Malaysia.

E-mail: sreeramanan@usm.my.

Received: 13 April 2015;

Revised: 05 September 2015;

Accepted: 07 September 2015;

Published Online: ??? 
the reduction of total leaf surface, early leaf senescence, damaged photosynthesis apparatus and inability of plant to produce sufficient food (Noctor et al., 2002). The effects of such abiotic stress are not uniform and vary from prolonged duration with extremely low precipitation, to short duration with the absence of rainfall where survival of the affected vegetations depends completely on the underground soil water (Lafitte et al., 2006). Polyethylene glycol (PEG) is widely used to stimulate in vitro drought stress condition in plants (Kaufman and Eckard 1971). According to Lawlor (1970), PEG is a non-penetrating inert osmotic agent that reduces the osmotic potential of nutrient solution and at the same time does not absorbed by the cell and not phytotoxic. Wahid and Rasul 2005 reported that various abiotic stresses for example drought stress and saline environment tend to heighten the production of reactive oxygen species (ROS) with a concomitant increase in the oxidative load in plants. The antioxidant enzymes such as SOD, CAT and APX are involved in the ROS scavenging systems.

The main abiotic stress that often affect the growth and survival of epiphytes such as orchids are insufficient water availability and prolonged drought period. Moreover due to drastic climate changes in recent years, habitats of epiphytes were directly influenced. Hence, studies focused at elucidating both biochemical and physiological responses of plants under drought stress are important and have gained considerable interest. Vandaceous orchids such as Aranda Broga Blue Bell which categorized under epiphytic orchid can grow well under high light intensity with high watering frequency. However, this orchid tends to dehydrate fast if watering frequency is not adequate especially during low precipitation. Thus, the present study was conducted with the objective of using in vitro cultures to elucidate the biochemical and physiological responses against drought condition induced by PEG 400 in PLBs of Aranda Broga Blue Bell.

\section{MATERIALS AND METHODS}

\section{Plant material}

PLBs of Aranda Broga Blue Bell were used for in vitro drought simulation study. The PLBs were cultured in Vacin and Went (1949) media supplemented with 15\% $(\mathrm{v} / \mathrm{v})$ fresh coconut water, $2 \%(\mathrm{w} / \mathrm{v})$ banana pulp and $2 \%(\mathrm{w} / \mathrm{v})$ potato extract. The PLBs were grown at $25^{\circ} \mathrm{C}$ under $16 \mathrm{~h}$ photoperiod using cool white fluorescent lamps $\left(150 \mu \mathrm{mol} \cdot \mathrm{m}^{-2} \cdot \mathrm{s}^{-1}\right)$. PLBs were subcultured every four weeks and newly developed PLBs in the range of 3 to $4 \mathrm{~mm}$ were used as explants for the following experiments.

\section{In vitro drought treatment}

Four weeks old PLBs (3-4mm) were selected and cultured on Vacin and Went medium (1949) supplemented with various concentration of PEG 400 [0 (control), 5, 10 and
$15 \%(\mathrm{v} / \mathrm{v})]$. The $\mathrm{pH}$ of the medium was adjusted to 4.9 prior to autoclaving. Viability, morphology, relative water content, total chlorophyll content and total soluble protein of treated PLBs were evaluated after 7 days. Meanwhile, antioxidant enzymes activities such as SOD, CAT and APX of treated PLBs were also determined in response to PEG-induced drought stress.

\section{Determination of viability and morphological changes of PLBs}

Effects of PEG 400 on viability of PLBs were determined by calculating the percentage of viable PLBs from the total number of treated PLBs. Non-viable PLBs were identified as bleaching or brown in colour while green PLBs were considered as viable.

\section{Determination of relative water content}

The determination of total water content was adapted from the protocol used by Lokhande et al. (2010). The fresh weight (FW) of the PLBs was determined immediately after selected from the four weeks old PLBs culture and blotted with tissue paper to remove the excess water. Dry weight (DW) was measured after drying the PLBs at $60^{\circ} \mathrm{C}$ in the hot air oven for $48 \mathrm{~h}$. The percentage of the tissue water content (TWC \%) of the PLBs was determined using the following equation:

$$
\operatorname{TWC}(\%)=\left[\frac{\mathrm{FW}-\mathrm{DW}}{\mathrm{DW}}\right] \times 100
$$

\section{Total chlorophyll content}

The chlorophyll determination assay was adapted and modified from the protocol used by Harborne (1973). For the extraction of chlorophyll samples, $0.5 \mathrm{~g}$ of fresh PLBs from each treatment samples were crushed with $1.0 \mathrm{~g}$ of calcium carbonate $\left(\mathrm{CaCO}_{3}\right)$ powder and $5 \mathrm{~mL}$ of $80 \%(\mathrm{v} / \mathrm{v})$ acetone solution using a pre-cooled chilled mortar and pestle $\left(4^{\circ} \mathrm{C}\right)$. The extract was filtered with Whatmann No. 1 filter paper, followed by washing the mortar and pestle with $80 \%(\mathrm{v} / \mathrm{v})$ acetone solution. The extraction volumes were added up to $25 \mathrm{~mL}$ using volumetric flask with $80 \%$ (v/v) acetone solution. The absorbance readings of the chlorophyll extracts were measured at $646 \mathrm{~nm}$ and $663 \mathrm{~nm}$ using spectrophotometer and the readings were taken 3 times for each sample. The total chlorophyll contents $(\mu \mathrm{g} / \mathrm{mL})$ were calculated using equations described by Harborne (1973):

Chlorophyll $\mathrm{a}=12.21 \mathrm{~A}_{663 \mathrm{~nm}}-2.81 \mathrm{~A}_{646 \mathrm{~nm}}$ Chlorophyll $b=20.13 A_{646 n m}-5.03 A_{663 n m}$ Total chlorophyll content $(\mu \mathrm{g} / \mathrm{mL})=17.30 \mathrm{~A}_{646 \mathrm{~nm}}-7.18 \mathrm{~A}_{663 \mathrm{~nm}}$

The results were expressed as $\mu \mathrm{g} / \mathrm{g}=\mu \mathrm{g} / \mathrm{mL} \times$ Extraction volume (mL)

Fresh weight (g) 


\section{Enzyme extraction}

Extraction of antioxidant enzymes from PLBs were based on the methods described by Samantary (2002) and Monnet et al. (2006). The extracts are used for determination of total soluble protein content and antioxidant enzymes activities. PLBs were homogenized using pre-cooled mortar and pestle in $10 \mathrm{~mL}$ extraction buffer with $2 \mathrm{mM}$ EDTA ferric sodium salt and $2 \%(\mathrm{w} / \mathrm{v})$ polyvinylpyrrolidone (PVP). The solution was then transferred into $1.5 \mathrm{~mL}$ Eppendorf tubes and centrifuged in a pre-cooled microcentrifuge $\left(4^{\circ} \mathrm{C}\right)$ at $9000 \mathrm{rpm}$ for $30 \mathrm{~min}$. Then the supernatant was transferred into $1.5 \mathrm{~mL}$ Eppendorf tubes and stored at $4^{\circ} \mathrm{C}$.

\section{Measurement of total soluble protein}

Total soluble protein in the enzyme extract was determined according to the method described by Bradford (1976). The absorbance reading was recorded at $595 \mathrm{~nm}$ and total soluble protein content was quantified by using Bovine Serum Albumin (BSA) as a standard.

\section{Superoxide dismutase (SOD) assay}

The determination of SOD (EC 1.15.1.1) activity was based on the methods used by Samantary (2002) and Monnet et al. (2006). The assay mixture contained 9.9mM L-methionine, $50 \mathrm{mM}$ potassium phosphate buffer ( $\mathrm{pH} 7.8), 57 \mu \mathrm{M}$ NBT$2 \mathrm{HCl}, 1 \%(\mathrm{w} / \mathrm{v})$ Triton-X, and $100 \mu \mathrm{L}$ of enzyme extract. The reaction was started with the addition of $1.3 \mu \mathrm{M}$ riboflavin and exposition under two 15W fluorescent lamps (Philips Tornado Energy Saver, Extra Bright, 950 lumen, $631 \mathrm{~mW}^{-1}$, Philips Electronics) for $15 \mathrm{~min}$. The lamps were placed $8 \mathrm{~cm}$ away from the reaction samples. The reaction was stopped by switching off the lamps. Tubes containing mixtures which is entirely lacking of the enzyme developed maximal purple colour. A non-irradiated mixture was used as the blank. The reduction in NBT-2HCl was calculated by monitoring the change in absorbance at $560 \mathrm{~nm}$. One unit $(\mathrm{U})$ of SOD was defined as the amount of the enzyme required to inhibit the photoreduction of $\mathrm{NBT}-2 \mathrm{HCl}$ by $50 \%$.

\section{Catalase (CAT) assay}

The determination of CAT (EC 1.11.1.6) activity was derived from the method used by Cakmak and Marschner (1992) and Monnet et al. (2006) with slight alterations. Total of $3.1 \mathrm{~mL}$ reaction mixture contains $100 \mathrm{mM}$ of potassium phosphate buffer (pH7.0) and $100 \mu \mathrm{L}$ of enzyme extract. The reaction was started with the addition of $6 \mathrm{mM}$ hydrogen peroxide $\left(\mathrm{H}_{2} \mathrm{O}_{2}\right)$ into the plastic cuvettes. The rate of decomposition of $\mathrm{H}_{2} \mathrm{O}_{2}$ was recorded using spectrophotometer at $240 \mathrm{~nm}$ for every $30 \mathrm{~s}$ up to $3 \mathrm{~min}$. One enzymatic unit of CAT is defined as the amount of enzyme required to decompose $1.0 \mu \mathrm{mol}$ of $\mathrm{H}_{2} \mathrm{O}_{2}$ at $\mathrm{pH} 7.0$ and $25^{\circ} \mathrm{C}$, with the $\mathrm{H}_{2} \mathrm{O}_{2}$ concentration falling from $10.3 \mathrm{mM}$ to $9.2 \mathrm{mM}$ (Claiborne 1985; Prabhakar et al., 2007).

\section{Ascorbate peroxidase (APX) assay}

APX (EC 1.11.1.11) activity was assayed according to the method described by Nakano and Asada (1981) with minor modifications. The $3.1 \mathrm{~mL}$ assay contained $100 \mathrm{mM}$ potassium phosphate buffer $(\mathrm{pH} 7.0)$ and $100 \mu \mathrm{L}$ of enzyme extract. The reaction was initiated with the addition of $6 \mathrm{mM}$ hydrogen peroxide $\left(\mathrm{H}_{2} \mathrm{O}_{2}\right)$. The rate of decomposition of $\mathrm{H}_{2} \mathrm{O}_{2}$ was recorded using spectrophotometer set at $290 \mathrm{~nm}$ for every $30 \mathrm{~s}$ up to $3 \mathrm{~min}$. One enzymatic unit of APX is defined as the amount of enzyme used to reduce hydrogen peroxide in one gram of fresh weight tissue.

\section{Statistical analysis}

Each replicates containing 10 PLBs and for each treatment 3 replicates were used for the experiments. Every experiment was conducted twice. The data were analyzed by one-way analysis of variance (ANOVA) using statistical software SPSS 20.0 (IBM Corp., Armonk, NY) and the means were compared by using Tukey's test at $\mathrm{P} \leq 0.05$.

\section{RESULTS}

\section{Effects of in vitro drought stress to morphology and viability of PLBs}

During preliminary study, PEG 400 and PEG 6000 was use to induce drought stress to evaluate the response of PLBs corresponding to different concentrations of PEG treatment $(0,5,10,15 \%)$ (Data not shown). PEG 400 was further adopted in the following experiment. The present study revealed that PLBs of Aranda Broga Blue Bell incubated on Vacin and Went (1949) medium supplemented with 5\% PEG 400 did not display any significant difference in terms of morphology and viability when compared to control (0\% PEG 400) (Fig. 1). Both control (Fig. 1a) and 5\% PEG 400 (Fig. 1b) treated PLBs maintained green and healthy after 7 days of in vitro drought treatment. On the other hand, unfavorable condition created by higher concentration of PEG 400 significantly reduces the viability of treated PLBs and the lowest viability percentage was recorded at 15\% PEG 400 treated PLBs (Fig. 2). Majority of the PLBs cultured in medium containing 10 and $15 \%$ PEG 400 turned brown or bleached (Fig. 1c and 1d) and the growth and development of PLBs were stunted.

\section{Effects of in vitro drought stress to relative water content of PLBs}

In the present study, the highest relative water content was recorded in PLBs incubated in control medium where the uptake of water molecules by plant cells occurred without interference from drought-inducing chemical, PEG 400 (Fig. 3). PLBs grown on medium supplemented with PEG 400 showed a reduction in relative water content. PEG 400 treatment at 15\% significantly produce the lowest 


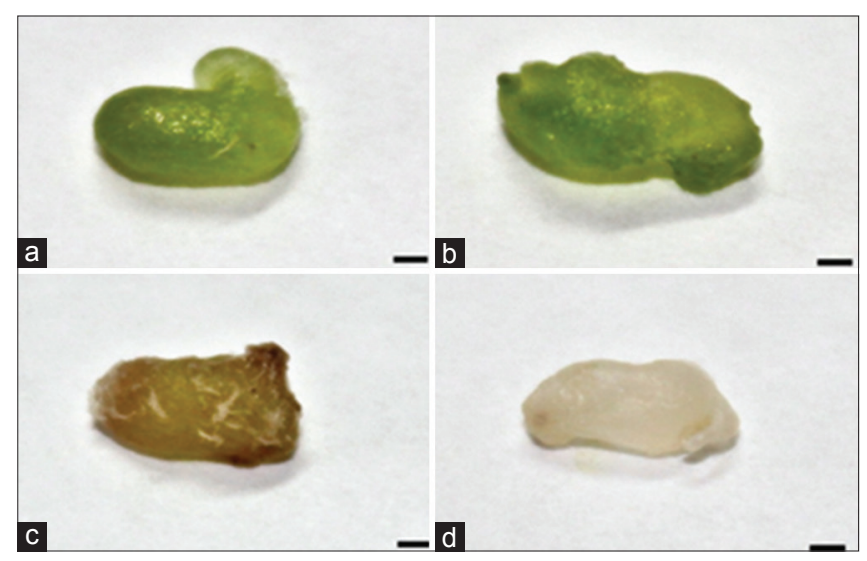

Fig 1. Morphological changes in PLBs of Aranda Broga Blue Bell on Vacin and Went (1949) medium supplemented with (a) 0; (b) 5; (c) 10 ; (d) $15 \%(\mathrm{v} / \mathrm{v})$ of PEG 400 after seven days of treatment. The bar represents $0.1 \mathrm{~cm}$.

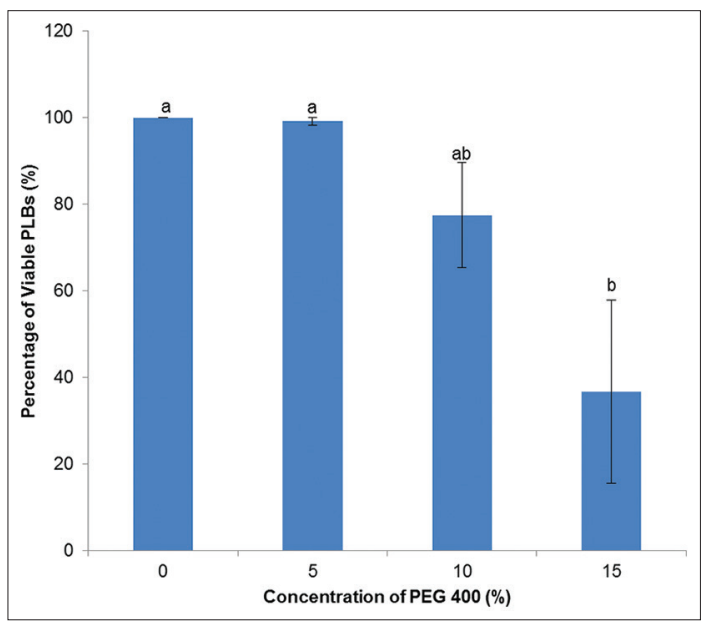

Fig 2. The percentage of viable PLBs of Aranda Broga Blue Bell cultured on Vacin and Went (1949) medium supplemented with various concentrations of PEG 400 after seven days of treatments. Means with the identical alphabets are not significantly different.

relative water content of treated PLBs compared to the control treatment PLBs.

\section{Effects of in vitro drought stress to chlorophyll content and total soluble protein of PLBs}

Chlorophyll and total soluble protein content of PLBs has been significantly reduced when PEG 400 was added to the culture media. As shown in Fig. 4, culturing PLBs in control medium without PEG 400 recorded the highest total chlorophyll content followed by PLBs treated with 5\%,10\% and 15\% PEG 400. According to the statistical analysis, data obtained from all treatments were significantly different except for media containing 10\% and 15\% PEG 400. Similar to chlorophyll content, the highest total soluble protein was observed in PLBs cultured in control treatment (Fig. 5). In vitro drought stress by PEG 400 significantly reduces total soluble protein of treated PLBs and as the concentration

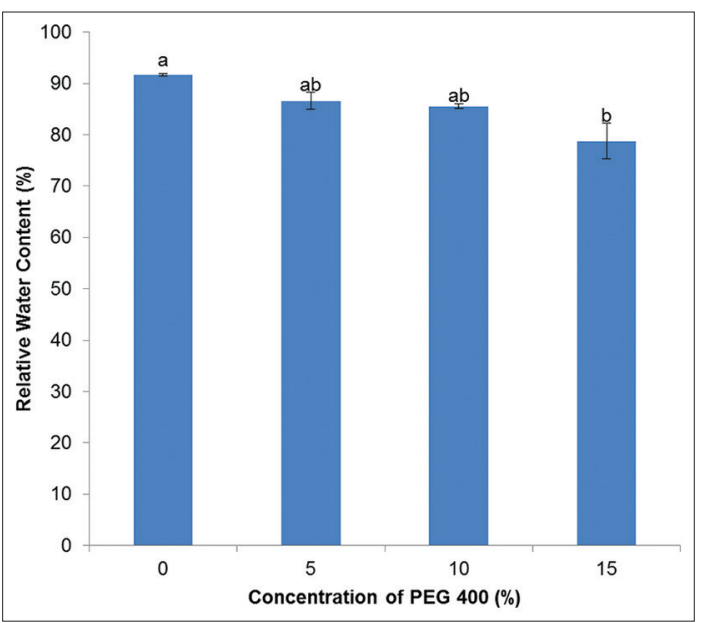

Fig 3. The relative water content of PLBs of Aranda Broga Blue Bell cultured on Vacin and Went (1949) medium supplemented with various concentrations of PEG 400 after seven days of treatments. Means with the identical alphabets are not significantly different.

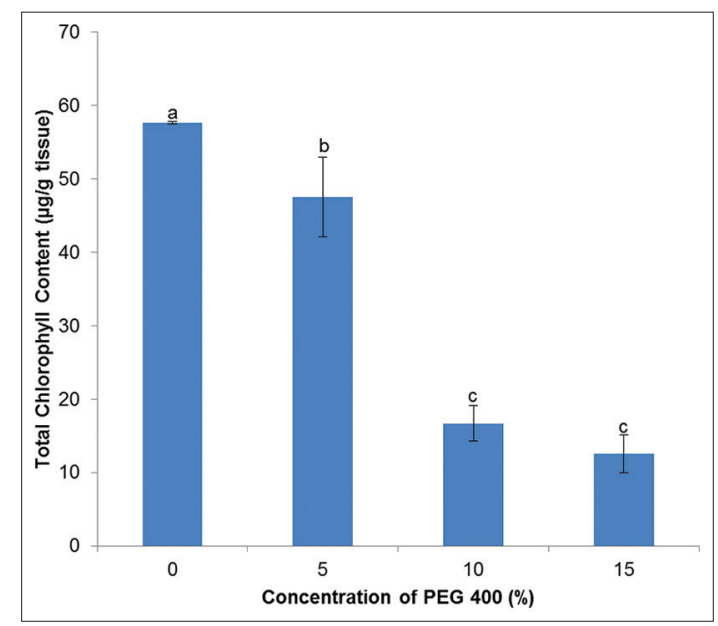

Fig 4. The total chlorophyll content of PLBs of Aranda Broga Blue Bell cultured on Vacin and Went (1949) medium supplemented with various concentrations of PEG 400 after seven days of treatments. Means with the identical alphabets are not significantly different.

increases, PLBs displayed lower concentration of total soluble protein.

\section{Effects of in vitro drought stress to SOD, CAT and APX antioxidant activity of PLBs}

Antioxidant activities of PLBs displayed prominent impact when PEG 400 was added in culture media. Based on Fig. 6, control treatment and PLBs cultured in 5\% PEG 400 resulted in relatively low total SOD activities. The SOD activities of PLBs treated with 10 and 15\% PEG 400 were then significantly induced to overcome mass production of ROS. Similar pattern of antioxidant activity was also exhibited by CAT activity (Fig. 7). As concentration of PEG 400 increases, CAT activity of treated PLBs increases. Nevertheless, control treated PLBs produced higher CAT activity compared to 5\% PEG 400 treated PLBs. Besides 


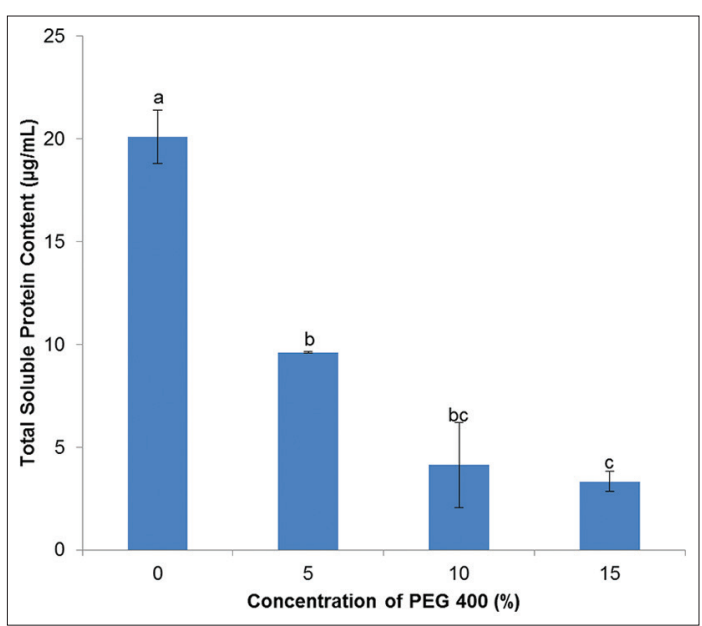

Fig 5. The total soluble protein content of PLBs of Aranda Broga Blue Bell cultured on Vacin and Went (1949) medium supplemented with various concentrations of PEG 400 after seven days of treatments. Means with the identical alphabets are not significantly different.

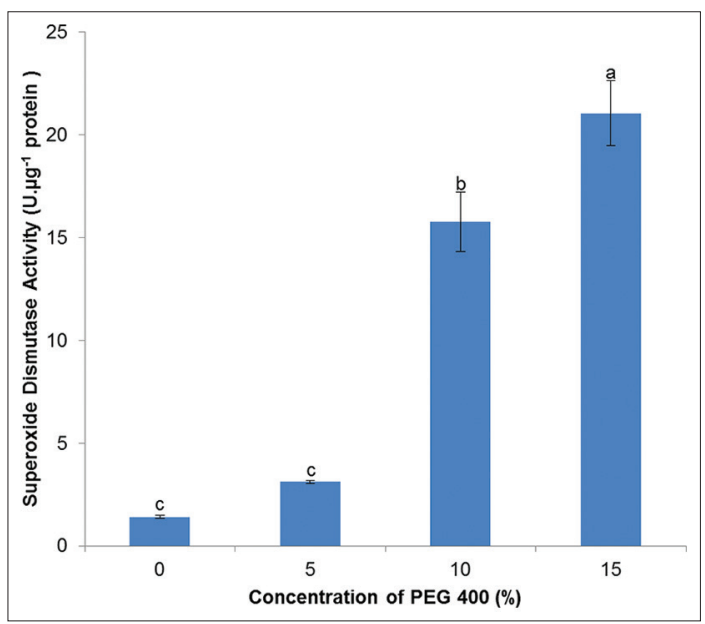

Fig 6. The superoxide dismutase activity of PLBs of Aranda Broga Blue Bell cultured on Vacin and Went (1949) medium supplemented with various concentrations of PEG 400 after seven days of treatments. Means with the identical alphabets are not significantly different.

that, present study also implied that the activity of APX was observed highest in PLBs treated with 5\% PEG 400 (Fig. 8). Unfortunately, high level of PEG 400 at $10 \%$ and $15 \%$ did not increase the activity of APX.

\section{DISCUSSION}

In vitro drought stress using high concentration of PEG 400 significantly reduces the morphology and viability of PLBs. PEG 400 at the lowest concentration tested, which is $5 \%$ did not lead to any negative impact towards the treated PLBs as the results obtained was not significant compared to control. Browning and bleaching of PLBs were observed when PLBs were treated with PEG 400 at concentration higher than 5\% (Fig. 1). This may probably due to the effects of oxidative damage as a result of

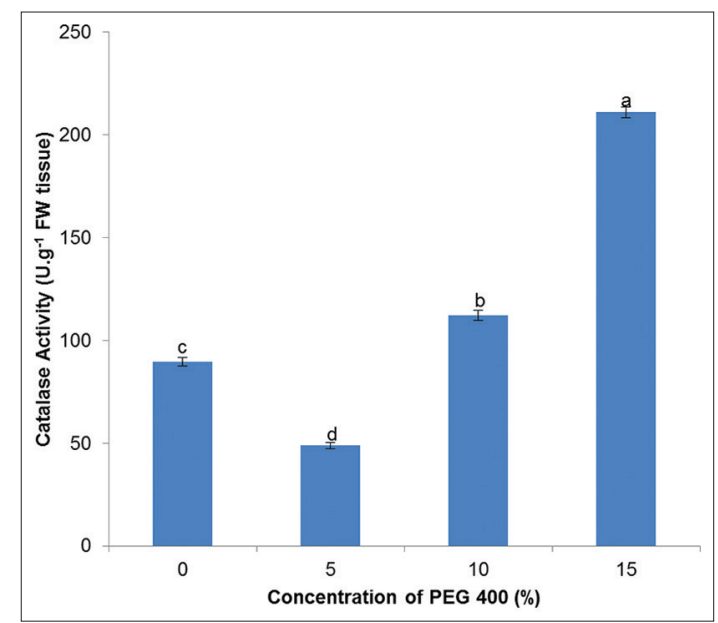

Fig 7. The catalase activity of PLBs of Aranda Broga Blue Bell cultured on Vacin and Went (1949) medium supplemented with various concentrations of PEG 400 after seven days of treatments. Means with the identical alphabets are not significantly different.

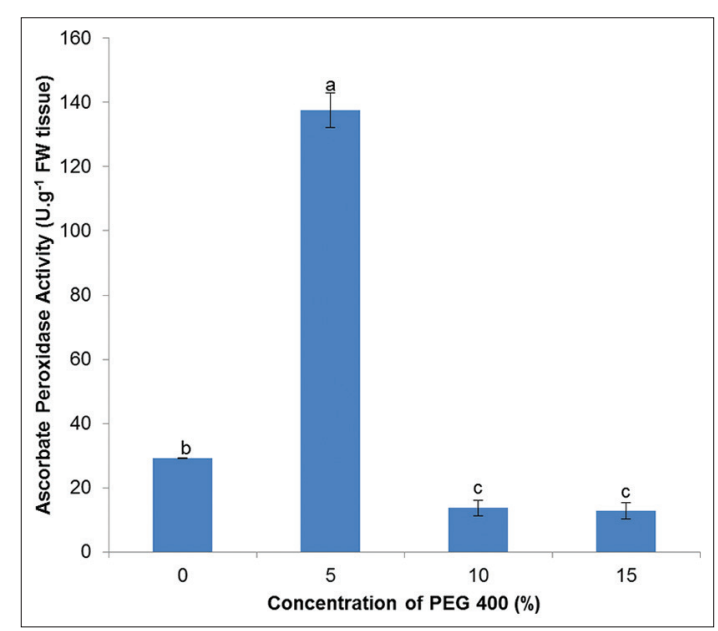

Fig 8. The ascorbate peroxidase activity of PLBs of Aranda Broga Blue Bell cultured on Vacin and Went (1949) medium supplemented with various concentrations of PEG 400 after seven days of treatments. Means with the identical alphabets are not significantly different.

drought stress which further caused the degradation of chlorophyll, a photosynthetic pigment that gives plant their green appearance (Ashraf and Harris 2013). According to Ishtiaq et al. (2013), browning of explants is a process called phenolic oxidation which is due to the production of phenolic compounds where it is directly triggered by biotic and abiotic stresses. It can be concluded that PLBs grown on medium supplemented with PEG 400 synthesized specific phenolic compounds to adapt themselves in water deficit condition. The severity of in vitro drought stress effects depends on the concentration of PEG 400 and the duration of treatment. PLBs were unable to withstand higher concentration of PEG 400 and at 10\% and 15\% PEG 400 treatment, browning and bleaching of PLBs were observed, subsequently causing reduction in viability (Fig. 2). Although the durations of in vitro drought 
condition were uniform for every treatment, PLBs treated with high concentration of PEG 400 showed significant morphological changes and unable to develop properly. Similar to studies reported by Soni et al. (2011), several physiological response of moth beans cultivars to $15 \%$ PEG treatment was observed such as leaf shrinking, yellowing of root tips and leaf curling after 7 days. Ishtiaq et al. (2013) reported that the tissue browning severely inactivated the growth and development of the in vitro explants. Besides that, oxidation of secondary metabolites also resulted in browning of culture medium in which it blocks the absorption of nutrients and leads to death of explants.

One of the typical characteristics of polyethylene glycol is that it is able to reduce water potential of the rooting medium and water potential of the plant (Lawlor 1970). The addition of PEG 400 into the medium decreased the water potential which later results in progressive reduction in relative water content of PLBs. In the present study, relative water content was recorded highest in PLBs incubated in control medium, where the water potential of the medium was higher compared to the water potential of PLBs (Fig. 3). Therefore, as in normal conditions, the rate of absorption of water molecules from growth medium by unstressed PLBs was relatively high. According to Ackay et al.(2010), both peanut cultivar Florispan and Gazipasa significantly exhibited greater water deficit at $-0.8 \mathrm{MPa}$ compared to $-0.4 \mathrm{MPa}$ PEG treatment. Similar to studies reported by Ozkur et al.(2009), Caper (Capparis ovata Desf.) seedlings treated with PEG 6000 for 7 days have shown decrease in relative water content compared to control.

Significant decrease in total chlorophyll content of the PLBs treated with PEG 400 may be caused by the increased degradation of chlorophyll pigments due to drought induced metabolic imbalance (Fig. 4). Reduction in chlorophyll and other photosynthetic pigments have been reported in some earlier studies on different plants including wheat (Arfan et al., 2007), castor bean (Pinheiro et al., 2008) and sunflower (Akram and Ashraf 2011) in response to abiotic stress. According to Ashraf and Harris (2013), early stages of drought stress stimulate the stomatal closure as a response to the production of abscisic acid. The closure of stomata inhibits the entry of carbon dioxide and accumulates oxygen molecules. Therefore, such situation increased the rate of photorespiration which leads to the oxidative damage of chloroplast components especially chlorophyll.

Results obtained displayed that there were strong correlations between total protein content and total chlorophyll content of PLBs of Aranda Broga Blue Bell under in vitro drought conditions induced by PEG 400. Present study revealed that total chlorophyll content of PLBs decreased as the intensity of in vitro drought simulation increased. In other words, degradation of photosynthetic pigments implied that the rate of photosynthesis also decreased. Evidently, water deficit condition negatively affects photosynthesis process and materials needed for protein synthesis are not provided (Mohammadkhani and Heidari 2008). Therefore, reduction of total soluble protein in PLBs cultured on medium supplemented with PEG 400 was due to the shortage of important materials for protein synthesis (Fig. 5). Besides that, the enhanced protein degradation was also due to the activity of proteinases, an enzyme that responsible in lowering the protein content in a cell. Vacuole is the site of production of proteinase and in normal condition, rate of protein synthesis and protein degradation is balanced. However, water stress leads to the breach of tonoplast and results in the leakage of proteinase into other cellular compartments. Such situation will definitely initiate uncontrolled protein degradation. In addition, the changes in total soluble protein against drought stress were consistent with previous studies on soybean (Bensen et al., 1988) and maize (Riccardi et al., 1998).

One of the biochemical effects of drought stress condition is the overproduction of reactive oxygen species (ROS). Chloroplast, peroxisome and mitochondria are the major sites of production of these free radical molecules. SOD is the first line of plant defense system against uncontrolled oxidation during unfavorable conditions. Cruz de Carvalho (2008) reported that scavenging activity of SOD includes the conversion of highly reactive singlet oxygen molecules into more stable hydrogen peroxide. In the present investigation, SOD activity was significantly the highest in stressed as compared to control PLBs (Fig. 6).

Present study also revealed the role of CAT in completing the scavenging activity of SOD. Unlike SOD, CAT is capable to completely detoxify hydrogen peroxide. However, the activity of this antioxidant enzyme is limited within the peroxisomes. In the present experiment, CAT activity in PLBs cultured on medium with 5\% PEG 400 was significantly lower than CAT activity in unstressed PLBs (Fig. 7). Perhaps this might be due to the low affinity of CAT towards hydrogen peroxide. Cruz de Carvalho (2008) stated that the enzyme CAT has low affinity for hydrogen peroxide and effective only in high concentration of hydrogen peroxide. In fact, high concentration of PEG 400 in culture medium induced excessive production of hydrogen peroxide in PLBs which was favorable to the enzyme CAT.

Another antioxidant enzyme, APX has high affinity for hydrogen peroxide and can be found in all reactive oxygen 
species production site. Shigeoka et al. (2002) claimed that the APX exist as isoenzymes and has an important role in metabolism of hydrogen peroxide in higher plants. In addition, APX is known to localize in at least three different cellular compartments including chloroplast, mitochondria and peroxisome. Lower APX activity of treated PLBs at $10 \%$ and $15 \%$ PEG 400 (Fig. 8) could be due to the impact of drastic degradation of chloroplast as shown in Fig. 4. This also implied that the APX isoenzyme in chloroplast plays a greater role in regulating the hydrogen peroxide level. Present study also showed that the controlled production of antioxidant enzymes also occurred in control PLBs. These enzymes played a major role in maintaining the optimum level of reactive oxygen species which were involved in plant signaling and defense mechanism (Cruz de Carvalho 2008).

\section{CONCLUSION}

It can be concluded that PLBs of Aranda Broga Blue Bell is very sensitive towards in vitro drought conditions induced by PEG 400. Physiological and biochemical response of the PLBs to various concentrations of PEG 400 treatment has been revealed. In summary, Aranda Broga Blue Bell PLBs is drought tolerant to low concentration of PEG 400 but could not withstand more than $10 \%$ of PEG 400 treatment. Future research could be focused in generating a mutant that has high tolerance level under in vitro drought condition. The drought tolerance PLBs could be grown into complete orchids and tested for in vivo drought stress conditions in future.

\section{Author's contribution}

Mohd. Aminur Faiz Bin Suis conducted the experiments and wrote the initial manuscript. Khor Soo Ping provided assistance throughout the experiments and wrote part of the manuscript. Chin Chee Keong assisted in data collection and statistical analysis. Sreeramanan Subramaniam supervised and contributed to the implementation of this project.

\section{ACKNOWLEDGEMENTS}

The authors would like to thank the Universiti Sains Malaysia Research University Grant Scheme (USM-RU 2012) for supporting this study.

\section{REFERENCES}

Akcay, U. C., O. Eercan, M. Kavas, L. Yildiz, C. Yilmaz, H. A. Octem and M. Yucel. 2010. Drought-induced oxidative damage and antioxidant responses in peanut (Arachis hypogaea L.) seedlings. Plant Growth Regul. 61: 21-28.
Akram, M. S. and M. Ashraf. 2011. Exogenous application of potassium dihydrogen phosphate can alleviate the adverse effect of salt stress on sunflower (Helianthus annuus L.). J. Plant Nutr. 34: 1041-1057.

Arfan, M., H. R. Athar and M. Ashraf. 2007. Does exogenous application of salicylic acid through the rooting medium modulate growth and photosynthetic capacity in differently adapted spring wheat cultivars under salt stress? J. Plant Physiol. 164: 685-694.

Ashraf, M. and P. J. C. Harris. 2013. Photosynthesis under stressful environments: An overview. Photosynthetica. 51: 163-190.

Bensen, R. J., J. S. Boyer and J. E. Mullet. 1988. Water deficit-induced changes in abscisic acid, growth, polyamines, translatable RNA in soybean hypocotyls. Plant Physiol. 88: 289-294.

Bradford, M. M. 1976. A rapid and sensitive method for the quantitation of microgram quantities of protein utilizing the principle of protein-dye binding. Anal. Biochem. 72: 248-254.

Cakmak, I. and H. Marschner. 1992. Magnesium deficiency and high light intensity enhance activities of superoxide dismutase, ascorbate peroxidase, and glutathione reductase in bean leaves. Plant Physiol. 98: 1222-1227.

Claiborne, A. 1985. Catalase activity. In: R. A. Greenwald (Ed.), Handbook of Methods for Oxygen Radical Research, CRC Press, Boca Raton, Pp. 284-284.

Cruz de Carvalho, M. H. 2008. Drought stress and reactive oxygen species: Production, scavenging and signaling. Plant Signal Behav. 3: 156-165.

Gantait, S. and U. R. Sinniah. 2012. Rapid micropropagation of monopodial orchid hybrid (Aranda Wan Chark Kuan 'Blue' $\times$ Vanda coerulea Grifft. ex. Lindl.) through direct induction of protocorm-like bodies from leaf segments. Plant Growth Regul. 68: 129-140.

Godo, T., M. Komori, E. Nakaoki, T. Yukawa and K. Miyoshi. 2010. Germination of mature seeds of Calanthe tricarinata Lindl., an endangered terrestrial orchid, by asymbiotic culture in vitro. In Vitro Cell. Dev. Biol. Plant. 46: 323-328.

Harborne, J. B. 1973. Phytochemical Methods: A Guide to Modern Techniques of Plant Analysis, Chapmann and Hall Limited, London.

IBM Corp. Released 2011. IBM SPSS Statistics for Windows, Version 20.0, Armonk, NY: IBM Corp.

Ishtiaq, A., H. Tanveer, A. Irfan, N. Muhammad, M. N. Maryam, R. Muhammad and I. Muhammad. 2013. Lethal effects of secondary metabolites on plant tissue culture. Am. Eurasian J. Agric. Environ. Sci. 13: 539-547.

Kaufmann, M. R. and A. N. Eckard. 1971. Evaluation of water stress control with polyethylene glycols by analysis of guttation. Plant Physiol. 47: 453-456.

Khodarahmpour, Z. 2011. Effect of drought stress induced by polyethylene glycol (PEG) on germination indices in corn (Zea mays L.) hybrids. Afr. J. Biotechnol. 10: 18222-18227.

Lafitte, H. R., Z. K. Li, C. H. M. Vijayakumar, Y. M. Gao, Y. Shi, J. L. Xu, B. Y. Fu, S. B. Yu, A. J. Ali, J. Domingo, R. Maghirang, R. Torres and D. J. Mackill. 2006. Improvement of rice drought tolerance through backcross breeding: Evaluation of donors and selection in drought nurseries. Field Crops Res. 97: 77-86.

Lawlor, D. W. 1970. Absorption of polyethylene glycols by plants and their effects on plant growth. New Phytol. 69: 501-513.

Lee, Y. H. 1987. Cytology and fertility of an intergeneric orchid hybrid. J. Hered. 78: 319-322.

Lee, Y. H. 1991. Genomic constitutions and flower characteristics of selected Aranda orchid cultivars. Euphytica. 54: 251-254.

Lokhande, V. H., T. D. Nikam and S. Penna. 2010. Biochemical, 
physiological and growth changes in response to salinity in callus cultures of Sesuvium portulacastrum L. Plant Cell Tiss. Org. 102: 17-25.

Mohammadkhani, N. and R. Heidari. 2008. Effects of drought stress on soluble proteins in two maize varieties. Turk. J. Biol. 32: 23-30.

Monnet, F., F. Bordas, V. Deluchat and M. Baudu. 2006. Toxicity of copper excess on lichen Dermatocarpon luridum. Antioxidant enzyme activities. Chemosphere. 65: 1806-1813.

Nakano, Y. and K. Asada. 1981. Hydrogen peroxide is scavenged by ascorbate-specific peroxidase in spinach chloroplasts. Plant Cell Physiol. 22: 867-880.

Noctor, G., S. Veljovic-Jovanovic, S. Driscoll, L. Novitskaya and C. H. Foyer. 2002. Drought and oxidative load in the leaves of C3 plants: A predominant role for photorespiration? Ann. Bot. 89: 841-850.

Ozkur, O., F. Ozdemir, M. Bor and I. Turkan. 2009. Physiochemical and antioxidant responses of the perennial xerophyte Capparis ovata Desf. to drought. Environ. Exp. Bot. 66: 487-492.

Paek, K., E. Hahn and S. Park. 2011. Micropropagation of Phalaenopsis orchids via protocorms and protocorm-like bodies. In: T.A. Thorpe, and E. C. Yeung (Eds.), Plant Embryo Culture: Methods and Protocols, Springer, New York, Pp. 293-306.

Pinheiro, H. A., J. V. Silva, L. Endres, V. M. Ferreira, C. A. Câmara, F. F. Cabral, J. F. Oliveira, L. W. T. Carvalho, J. M. Santos and B. G. Santos Filho. 2008. Leaf gas exchange, chloroplastic pigments and dry matter accumulation in castor bean (Ricinus communis L.) seedlings subjected to salt stress conditions. Ind. Crop Prod. 27: 385-392.
Prabhakar, K. R., V. P. Veerapur, P. Bansal, V. K. Parihar, K. M. Reddy, P. B. Kumar, K. L. Priyadarsini and M. K. Unnikrishnan. 2007. Antioxidant and radioprotective effect of the active fraction of Pilea microphylla (L.) ethanolic extract. Chem. Biol. Interact. 165: 22-32.

Riccardi, F., P. Gazeau, D. De Vienne and M. Zivy. 1998. Protein changes in response to progressive water deficit in maize, quantitative variation and polypeptide identification. Plant Physiol. 117: 1253-1263.

Samantary, S. 2002. Biochemical responses of Cr-tolerant and Cr-sensitive mung bean cultivars grown on varying levels of chromium. Chemosphere. 47: 1065-1072.

Shigeoka, S., T. Ishikawa, M. Tamoi, Y. Miyagawa, T. Takeda, Y. Yabuta and K. Yoshimura. 2002. Regulation and function of ascorbate peroxidase isoenzymes. J. Exp. Bot. 53: 1305-1319.

Soni, P., M. Rizwan, K. V. Bhatt, T. Mohapatra and G. Singh. 2011. In vitro response of Vigna aconitifolia to drought stress induced by PEG-6000. J. Stress Physiol. Biochem. 7: 108-121.

Vacin, E. F. and F. W. Went. 1949. Some pH changes in nutrient solutions. Bot. Gaz. 110: 605-613.

Wahid, A. and E. Rasul. 2005. Photosynthesis in leaf, stem, flower, and fruit. In: Pessarakli, M., (Ed.), Handbook of Photosynthesis, $2^{\text {nd }}$ ed. CRC Press, Florida, Pp. 479-497.

Yue, G. H., L. T. Lam-Chan and Y. Hong. 2006. Development of simple sequence repeat (SSR) markers and their use in identification of Dendrobium varieties. Mol. Ecol. Notes. 6: 832-834.

Zainol, R. 2003. Potential new Aranda orchid hybrids for cut flowers. In: Book of Abstracts: $5^{\text {th }}$ National Congress on Genetics, Kuala Lumpur, Malaysia, Pp. 100-101. 